\title{
Usos e limites da teoria da escolha racional da religião
}

Ricardo Mariano

Este artigo tem por objetivo apresentar e analisar as principais concepções teóricas propostas por Rodney Stark, Roger Finke e Laurence I annaccone, pesqui sadores que formularam a teoria da escol ha racional da religião. Sem pretender ser exaustivo, enfoca seus usos, inovações e limitações, e o debate teórico que suscitaram, examinando as noções de racionalidade, desregulação estatal da religião, monopólio, pluralismo, competição, mercado, oferta, demanda e stricteness.

A teoria da escolha racional da religião veio a público nos anos de 1980 com os trabalhos do sociólogo norteamericano Rodney Stark. Em 1985, elepublicou, com W illiam SimsBainbridge, Thefuture of religion, composto por duas dezenas de artigos escritos entre 1980 e 1983. Em 1987, ambos lançaram A theory of religion, livro em que definiram sete axiomas sobre a condição humana, 104 conceitose 344 proposições contingentes. Prolífico, Stark passou a colaborar com o economista Laurence lannaccone e com 0 sociólogo Roger Finke nos anos seguintes, publicando dezenas de artigos e al guns novos livros. No início da década de 1990, com poucos anos de existência, essa perspectiva foi alçada à condição de "novo paradigma" teórico da sociologia da religião (cf. Warner, 1993). Tal reconhecimento, ao mesmo tempo queatestou sua influência, fez recrudescer a discussão a seu respeito. No final da década, Stark e Finke revisaram a teoria, com a intenção de reforçar o núcleo desua argumentação original, por meio da compilação de 
novos dados empíricos favoráveis à sua perspectiva, da lapidação e ampliação de seu leque deidéias, da real ização de pequenas correções conceituaise da formulação de novas respostas na tentativa de rebater as críticas de adeptos e adversários (cf. Stark, 1999a; Stark eFinke, 2000).

Por seu valor heurístico e seu caráter provocativo e desafiador, a teoria da escolha racional da religião tornou-se objeto de acalorado debate entre sociólogos norte-americanos e europeus nas duas últimas décadas. 0 estilo triunfalista e autocongratulatório dos escritos de Stark, observa R hys W iIliams (2000), contribuiu para incitar a combatividade dos adversários. Entre eles, destaca-se o sociólogo escocês Steve Bruce (1999), cujo livro Choice and religi on: a critique of rational choice theory, visava, entre outras coisas, a cravar uma estaca no peito do vampiro da teoria da escolha racional da religião. No mesmo ano, Stark (1999b) deu o troco, ao intitular um artigo, "Secularization, R.I.P", avesso à teoria da secularização defendida por Bruce, com um acrônimo - do termo latim requiescat in pace- presente em túmulos nos Estados U nidos. D e modo geral, porém, as principais polêmicas nessa área são de caráter estritamente acadêmico e distantes dos idiossincráticos estilos e personalidades de seus oponentes mais radicais. E, tal como ocorre nos debates em subáreas da sociologia e da ciência política contemporâneas, há, de um lado, os que consideram as abordagens sociológicas originadas da microeconomia e baseadas na teoria da escolha racional dotadas de grande cientificidade, simplicidade e capacidade de explicação e predição, e, de outro, os que defendem que elas ignoram o social, a história e as mediações culturais, e se revel am cegas diante de constrangimentos institucionais e estruturais, considerando-as um misto de imperialismo e reducionismo economicistas (cf. Baert, 1997).

Racionalidade maximizadora

Baseado na filosofia da ciência de Karl Popper, nos trabalhos de G eorge H omans, Peter Blau e James Coleman, e em insights da microeconomia, Stark defende o caráter preditivo da ciência, a noção de que teorias científicas começam por axiomas dos quais são deduzidas proposições empíricas falsificáveis e o foco analítico da teoria da escolha racional. D a mesma forma que John Stuart M ill propôs que a ciência econômica deveria empregar método dedutivo baseado no axioma de que os homens preferem uma quantidade de riqueza maior a uma menor (cf. Abramovay, 2004, p. 41), Stark postula que "os seres humanos buscam o que percebem ser recompensas e 
evitam o que percebem ser custos" (1997, pp. 6-7). Eis a premissa básica dessa teoria.

No plano religioso, "as pessoas fazem escolhas da mesma maneira que fazem outras escolhas, pesando custos e ben efícios" (Stark, 1999a, p. 265). $\mathrm{Na}$ busca por benefícios, segundo Stark (cf. Idem, p. 265), os seres humanos "querem religião" por ser a única fonte plausível de certas recompensas, incluindo aquelas indisponíveis aqui e agora para todos - como a tão desejada vida após a morte -, para as quais, a seu ver, há uma "demanda geral e inexaurível". N essa formulação, tal demanda parece independer da ação dos produtores religiosos e dos contextos históricos e culturais, o que, além desociologicamente problemático, torna a secularização, em teoria, impossível (cf. Sharot, 2002, pp. 433-434). Bruce (1999, p. 57) se opõe ao pressuposto de que a "condição humana nos confere uma necessidade permanente" de recompensas sobrenaturais, questionando a existência de uma religiosidade intrínseca aos seres humanos.

Para obter recompensas religiosas, os indivíduos procuram utilizar e manipular o sobrenatural, efetuando relações de troca com os deuses (cf. Stark, 1999a, pp. 269-270). As trocas com deuses poderosos, atentos às necessidades dos devotos e capazes de prover recompensas extramundanas, tendem a gerar custos mais elevados e relacionamento exclusivo de longo prazo (cf. I dem, pp. 275-277). As organizações religiosas, portanto, "serão capazes de requerer compromissos exclusivos e longos à medida que oferecerem recompensas extramundanas" (I dem, p. 279). N esse ponto, Stark (cf. I dem, pp. 281-282) sustenta a distinção sociológica clássica entre religião e magia, observando que a primeira, por centrar-se numa relação de troca com os deuses e na oferta de recompensas extramundanas de longo prazo, tende a gerar compromissos estáveis, duradouros e institucionalmente organizados, enquanto a última, baseada na coação e manipulação de forças sobrenaturais e na oferta de recompensas pontuais, imediatistas e mundanas, tende a formar clientela.

As trocas que envolvem custos e compromissos de longo prazo com vistas à obtenção de recompensas extramundanas, como a sal vação paradisíaca, implicam risco, já que estas não podem ser efetivamente demonstradas. C omo confiar, então, em sua veracidade? Problema universal da religião, segundo Stark (cf. Idem, p. 282), a confiança é gerada pela interação com os (e socialização dos) membros do grupo religioso, que depositam fé nessas recompensas e, assim, as legitimam internamente. D e modo que a pregação, o discipulado, os rituais, as orações, as experiências místicas, os 
milagres atribuídos às forças divinas e, sobretudo, os testemunhos de bênçãos recebidas, compartilhados coletivamente, são responsáveis por tornar confiáveis tais promessas extramundanas (cf. Idem, pp. 283-285).

Stark $(1997,1999$ a) reconhece que o raciocínio humano éum tanto não sistemático e intuitivo, e que a maximização freqüentemente é apenas parcial, mas acentua que seus postulados simples eformais sobre a condição ea racionalidadehumanas têm a vantagem de permitir a formulação demodelosmatemáticose explicações de alto nível. Baseado no conceito de racionalidade subjetiva de John Ferejohn e Raymond Boudon, Stark (1999a, p. 266) define racionalidade da seguinteforma: "D entro de seus limites deinformação e compreen são, restringidos pelas opções disponíveis, guiados por suas preferências e gostos, os seres humanos tentam fazer escolhas racionais". Fazer uma escolha racional significa sempre "tentar maximizar". A "intenção" do agente de maximizar "é tudo", segundo Stark (cf. Idem, p. 266), não importando se ele carece deinformação ou se age apoiado em cálculoserrados. 0 conceito de racionalidade subjetiva, portanto, não permite considerar irracional uma ação baseada na ignorância (cf. Sharot, 2002, p. 429). Pressupõe que os indivíduos agem de acordo com o que percebem ser de seu auto-interesse, mesmo nas situações em que não detêm o conhecimento necessário para avaliar em que el e consiste, o que, nesse caso, implica presumir sua percepção maximizadora do auto-interesse (cf. M ellor, 2000, pp. 279-280). D esse modo, a noção de racional idade dos teóricos do novo paradigma não supõeobjetivamenteuma ação maximizadora, antes postula uma atávica intenção de todo agente de maximizar suas escolhas, premissa quenão tem como ser refutada de forma empírica. N a prática, a subjetividade contida nessa racionalidade torna-a radicalmente distinta da noção de racionalidade da teoria econômica, que considera racional somente a ação em que o agente emprega meiosapropriados aos fins perseguidos e persegue fins mutuamente coerentes (cf. Sharot, 2002, p. 432).

Embora admita que a cultura, as normas e a socialização constrangem a ação dos indivíduos, Stark (1999a, p. 266) omite dos axiomas sobre a conduta racional a ação orientada por valores (wertrational), importantíssima na análise weberiana da religião (cf. Sharot, 2002, p. 430). Stephen Sharot (cf. I dem, pp. 430-431) afirma que a noção de racionalidade proposta por Stark familiariza-se com o tipo de ação com relação a fins (zweckrational), que orienta a ação econômica, analisada e considerada por W eber adversária da ação religiosa. A familiaridade apontada entre ambas as racionalidades limita-se, a meu ver, a seu caráter instrumental e à exclu- 
são de normas e valores, porém a religiosa difere da racionalidade objetiva presente na teoria econômica. M as a semelhança é suficiente para Sharot questionar a propriedade do uso, na análise sociológica da religião, de um conceito de racionalidade dotado de significado próximo ao de zweckrational. $\mathrm{H}$ aja vista que, na teoria weberiana, é a ação mágica que se aproxima da zweckrational, por ser orientada para o mundo e para fins imediatos e materiais, ao passo que a ação religiosa nas religiões de salvação, em contraste, tende a ser orientada para fins extramundanos e valores éticos (wertrational), tipo de orientação que leva muitos agentes a perseguir crenças e val ores independentemente dos custos envolvidos (cf. I dem, 2002, pp. 430-432). Como observa Richard Swedberg, segundo W eber, "nas religiões mais avançadas, os benefícios religiosos tendem a ser do outro mundo e não econômicos, e a atividade religiosa em si não é mais vista exclusivamente em termos de fins e meios, como nas religiões primitivas" (2005, p. 205).

À medida que a noção de racionalidade religiosa do novo paradigma define como racionais apenas as ações que tentam maximizar benefícios com o menor custo ou que estão a serviço do auto-interesse dos agentes, qual quer ação que não se encaixe nessa definição estrita se torna automaticamente não-racional e, portanto, excluída de sua abordagem. Com isso, descarta-se, em grande medida, o "papel dos fatores afetivos, simbólicos e emocionais no desenvolvimento de identidades coletivas" (M ellor, 2000, p. 277). Entretanto, dada a tendência de Stark e discípulos de hipertrofiar a racionalidade instrumental dos agentes, as ações baseadas na restrição do auto-interesse pela moral, como 0 altruísmo, tendem a ser reduzidas a um comportamento egoísta (cf. Jerolmack, 2004; M ellor, 2000, p. 282). Assim, 0 altruísmo só se torna passível de compreensão nessa perspectiva quando se transforma em seu oposto e perde seu sentido, passando a visar à auto-satisfação. 0 problema é que a racionalidade normativa, baseada na conformidade a valores e ideais morais, não pode ser reduzida empírica e conceitualmenteà racionalidadeinstrumental (cf. Jerolmack, 2004, pp. 141152). D isso resulta que desconsiderar a ação orientada por valores significa optar por restringir a capacidade de a sociologia compreen der o comportamento religioso. Ao considerá-la, contudo, resta evitar o erro de deduzir, automaticamente, comportamentos de valores religiosos.

0 lado positivo da perspectiva de considerar racionais escolhas e comportamentos religiosos consiste, de um lado, em "enfatizar mais o papel da agência humana nos processos religiosos" - ao menos no que concerne à 
escolha da religião - e, de outro, em desfazer-se de um sem-número de concepções preconceituosas, que os consideram, de saída, opiáceos, irracionais, patológicos, produtos da ignorância, de lavagem cerebral e de crises sociais (cf. Frigerio, 2000, p. 132).

0 lado problemático está no tipo estrito de racionalidade que supostamente anima as escolhas e os comportamentos religiosos. Constitui sério limite da teoria da escolha racional da religião sua ferrenha disposição de trabal har apenas com uma forma restrita de racionalidade, a instrumental ou maximizadora, por meio da qual procura enfeixar crenças, práticas e compromissos religiosos, tratando-os invariavelmente como ações auto-interessadas (cf. Jerolmack, 2004, p. 157). Tal reducionismo recobre as próprias definições de religião e compromisso religioso. Basta observar que, para Stark (1999a, pp. 270, 280), "a religião consiste de explicações muito gerais que justificam eespecificam ostermos detroca com um deus ou deuses", enquanto o "compromisso religioso é a condição em que os seres humanos prontamente satisfazem os termos de troca com um deus ou deuses conforme especificados pelas explicações de uma dada organização religiosa". Jerolmack (2004, p. 144) avalia que o fato de muitas pessoas vivenciarem a religião de modo abertamente instrumental não permite conceituá-la apenas "como uma relação de troca". A definição citada, porém, extrapola o restrito escopo traçado por J erolmack, tendo em vista quea religião aí consiste, em primeiro lugar, de explicações. D o ponto devista de Stark (1999a, p. 267), as explicações religiosas "auxiliam as pessoas a maximizar", por exemplo conferindo sentido à existência. Por isso, ele considera tais explicações recompensas concretas ofertadas pel os provedores aos consumidores religiosos.

O sentido dessa definição conceitual de religião, cabe notar, aproximase da interpretação weberiana a respeito do que atraía as pessoas para as diferentes religiões: os bens de salvação materiais e espirituais (cf. Swedberg, 2005). D a mesma forma, para W eber, os indivíduos têm necessidades de sentido (para lidar, por exemplo, com o sofrimento injusto e a morte) e interesses de compensação da insuficiência da existência terrena e de legitimação da boa fortuna, condicionados por suas posições sociais. Assim, aos desprivilegiados, a religião redentora promete "esperança de compensação" do sofrimento no outro mundo; aos privilegiados, oferece a "teodicéia da boa sorte", isto é, uma explicação para legitimar sua posição social dominante. Tanto para Stark como para Weber, são os produtores (profetas e teólogos formuladores de interpretações e explicações) e os reprodutores 
religiosos (sacerdotes e pregadores), por meio de seu trabal ho religioso, que conferem caráter e significação especificamente religiosos a tais interesses e necessidades. D aí a autonomia relativa da religião em relação aos determinismos sociais e econômicos. N ão obstante as semel hanças apontadas, Weber, em contraste, não formulou um conceito de religião, nem o restringiu a explicações sobre relações de troca entre homens e deuses ${ }^{1}$. Weber distingue-se ainda por analisar detidamente as crenças religiosas e seus variados efeitos na conduta dos fiéis. Já a perspectiva teórica abstrata de Stark tende, em certa medida, a relegá-las a segundo plano, ou, na opinião de seu crítico mais veemente (cf. Bruce, 1999), a ignorá-las.

\section{Economia religiosa}

A partir de meados da década de 1980, Stark, Finke e lannaccone passam a empregar insights básicos da teoria econômica para explicar os fenômenos religiosos em nível macrossocial, destacando duas noções: a de economia religiosa - que se refere à totalidade das atividades religiosas numa dada sociedade - e a de mercado religioso (cf. Stark, 1997, p. 16). Esses autores propõem que os sociólogos investiguem a economia religiosa tal como os economistas pesquisam a economia empresarial, realçando que ambas são compostas de firmas, linhas de produtos e serviços e consumidores. Eles não incorporam a noção de mercado à sua teoria apenas como uma boa e simples metáfora para auxiliar a compreensão do que ocorre nas economias religiosas. Tentam levar às últimas conseqüências sua adoção e aplicação, equiparando o máximo possível mercado econômico e mercado religioso einferindo, desse cotejo, várias proposições sobre o funcionamento das economias e firmas religiosas. Antes deles, cumpre observar, $M$ ax W eber, Peter Berger e Pierre Bourdieu aplicaram, de formas distintas e sem a mesma radicalidade economicista, diversas noções de extração econômica à análise da religião, como as de bens de salvação, interesse, monopólio, concorrência, oferta, demanda, capital, ganho, investimento.

Baseados no clássico A riqueza das nações, Stark e lannaccone (1993, p. 243) afirmam que, em vez de começarem, como M ax Weber e Richard Tawney, pela teologia para verificar seus efeitos na esfera econômica, foram conduzidos, inversamente, a mover-se dos princípios econômicos para os resultados religiosos sob a influência de Adam Smith, para quem 0 auto-interesse motiva tanto o clero como as empresas seculares, e os benefícios da competição, o peso do monopólio e o risco de regulação
1.Quanto à relação dessa teoria com os clássicos, Randall C 0llins(1997) mostraque a perspectiva de Stark se aproxima, em certos aspectos, da weberiana e se afasta da durkheimiana. M ellor (2000), por sua vez, a partir da teoriadareligião deD urkheim, criticao novoparadigma esuas concepções individualistas e racionalistas 
do Estado são tão reais na religião como em qualquer outro setor da economia.

O s expoentes da teoria da escolha racional da religião propõem que 0 foco analítico seja deslocado da demanda para a oferta religiosa, proposição que tem por efeito enfeixar as abordagens sociológicas da religião no interior dessa dicotomia. A versão radical dessa teoria, esboçada por Stark, Finke e lannaccone, parte do pressuposto de que a demanda religiosa é relativamente estável, o que justifica sua opção teórica por depositar as fichas da explicação na pesquisa da oferta religiosa. Isto é, sendo a demanda praticamente constante, os níveis de participação religiosa podem ser mais bem explicados em termos de oferta. Grosso modo, a ênfase teórica focada na oferta parte do pressuposto de que o destino dos grupos religiosos, em economias religiosas desreguladas pelo Estado, é fundamentalmente "uma função de suas estruturas organizacionais, de seus representantes de vendas, de seus produtos e de suas técnicas de marketing" (Wuthnow, 2005, p. 615).

Roger Finke defende essa nova perspectiva:

As explicações da mudança religiosa têm focado quase exclusivamente as mudanças na demanda por religião. 0 modelo de secularização, há longo tempo a teoria dominante na sociologia da religião, é baseado na premissa de que a religião declinará conforme a modernidade erode a demanda por crenças religiosas tradicionais. [...] A maioria das explicações oferecidas por historiadores e cientistas sociais supõe que as flutuações na atividade religiosa se devem a mudanças na demanda por religião. A fonte desta nova demanda é, com freqüência, atribuída vagamente a realinhamentos culturais, a mudanças na psique nacional, a ciclos econômicos, ou a uma fuga escapista da modernidade, dando-se pouca atenção à mudança nas ofertas. U ma abordagem baseada na oferta vira esta suposição de cabeça para baixo e afirma que as mudanças mais significativas na religião derivam da mudança na oferta, não da mudança na demanda (1997, p. 46).

O s mercados religiosos livres ou o grau de regulação estatal da religião constituem o principal fator que determina ou afeta as economias religiosas (cf. Stark, 1997, p. 17; Stark elannaccone, 1992, p. 2032). Finke(1997, pp. 49-51) observa que a regulação estatal, ao sustentar monopólios, perseguir, suprimir ou subsidiar certos grupos religiosos, muda os incentivos eoportunidades para os produtores religiosos, restringindo tanto a diversidade e a competição religiosas como as opções dos consumidores. Já a liberdade reli- 
giosa ou a abertura do mercado religioso, por meio da desregulação estatal, promove necessariamente o pluralismo religioso, tido como o "estado natural" das economias religiosas, já que os monopólios derivam sempre de re pressão estatal (cf. Stark e lannaccone, 1992, p. 2032). D ado que supor a total neutralidade estatal em relação aos grupos significa deparar-se fatalmente com sua impossibilidade empírica ou inexistência histórica, o que se analisa aí é o grau de regulação estatal das economias religiosas. Contudo, como o "grau" de regulação não épassível de mensuração, o quese observae se compara são os arranjos jurídicos e políticos que conformam as relações entreE stado eigrejas decada economia religiosa, eseu efeito sobrea liberdade e o pluralismo religiosos. $N$ essa tarefa, porém, os pesquisadores têm negligenciado a natureza das religiões em questão edado maior atenção àseconomias com mercados livres em detrimento das reguladas pelo Estado (cf. Bruce, 2000, p. 32).

0 maior número de grupos religiosos atuantes num determinado território, por sua vez, tende a acirrar a concorrência por sobrevivência e por mercado, compelindo-os a mobilizar seus agentes leigos e eclesiásticos, a exigir delesmaior compromisso, dedicação eativismo militante, a estimular o empreendedorismo, a optar por empregar técnicas eestratégias de evange lismo mais atraentes e eficazes ea adaptar-se às demandas de leigos e virtuais adeptos. Q uanto mai or o pluralismo, postula Stark (1997, p. 17), mais os grupos religiosos se especializarão no atendimento de diferentes demandas. Isto é, o pluralismo e o conseqüente acirramento da competição tendem a aumentar o volume, a diversificar ea mel horar o conjunto de bense serviços produzidos e ofertados pelos provedores religiosos e, dessa forma, a ampliar a probabilidade de atender aos interesses, às necessidades e às preferências dos distintos nichos e demandas do mercado, resultando na ampliação do recrutamento de novos fiéis. Em suma, desregulação estatal, liberdade, pluralismo e competição religiosos tendem a estimular o ativismo, a militância, a eficiência e o vigor das empresas religiosas, e a resultar na oferta de maior volume, diversidade equalidade de bense serviços religiosos e no suprimento de maior gama de demandas e preferências de segmentos específicos de mercado, elevando, assim, a mobilização e a participação religiosas da população (cf. Iannaccone, Finkee Stark, 1997).

Ao deslocarem o foco analítico da demanda para a oferta, Stark, Bainbridge, Finkeel annaccone inverteram radicalmentea teoria sociológica dominante acerca dos efeitos do pluralismo religioso sobre a religião, criando, segundo Stephen Warner (1993), um novo paradigma, pois atéentão o plu- 
2. Com 1350 denominações eseitas, conforme a Encyclopedia of American Religions, os Estados U nidos constituem uma das sociedades modernas mais pluralistasecom maior participação religiosa (cf. Shea, 2001). ralismo era considerado fator crucial de enfraquecimento da religião na modernidade. 0 dossel sagrado (lançado originalmente em 1969), de Peter Berger, consagrou, na sociologia da religião norte-americana dos anos de 1970 e 1980, a idéia de que o pluralismo religioso debilita a religião, por multiplicar o número de estruturas de plausibilidade concorrentes, relativizar o conteúdo dos discursos religiosos concorrentes, privatizá-los, subjetivá-los e, com isso, torná-los objetos de ceticismo, descrença e indiferença (cf. Berger, 1985). 0 exemplo histórico da vitalidadeda religião nosEstados U nidos, com seu notório pluralismo², por si só torna problemática a perspectiva teleológica de Berger. A idéia de que a multiplicação das estruturas de plausibilidade concorrentes acarreta necessariamente relativismo, descrédito e ceticismo religiosos, e, com isso, secularização, mostra-se frágil diante da evidência empírica da força das sei tas e das crenças e compromissos religiosos de seus membros nesse contexto religioso marcadamente liberal, tolerante, pluralista e desregulado pelo Estado.

Stark (1997, pp. 17-18) rejeita a visão de que o pluralismo competitivo seja uma força maligna que mina o vigor da religião. Ao contrário, defende que, quanto mais pluralista e competitiva for uma economia religiosa, maior será seu nível de participação religiosa. Inversamente, os níveis de compromisso e participação religiosos da população serão mais baixos nas economias religiosas dominadas por monopólios apoiados pelo Estado (cf. Stark e lannaccone, 1992, p. 2032). Por impedirem a competição e reunirem menor probabilidade de diversificar sua oferta de bens e serviços sem comprometer sua mensagem, os monopólios - a seu ver, impostos invariavelmente por regulação estatal - tendem a gerar comodismo nas lideranças, menor ativismo, eficiência evitalidade dos produtores religiosos, oferta menos volumosa e diversificada do quea provida na situação pluralista, e baixa aptidão para atender à diversidade das demandas religiosas. 0 smonopólios tendem a ser preguiçosos e oferecer um produto tépido, diminuindo o interesse e o consumo dos religiosos (cf. Stark elannaccone, 1992, p. 2033). As variações quantitativas na atividade e no consumo religiosos da população de determinada sociedade, portanto, dependem do vigor dos produtores de bens e serviços religiosos, vigor esse maior nos contextos em que os concorrentes religiosos são livres ou nos quais não sofrem regulação estatal. Para esses pesquisadores, os secularizados países europeus só não apresentam níveis departicipação religiosa mais al tos porquesuas economias religiosas são reguladas pelo Estado, o que debilita suas firmas religiosas e, por conseqüência, seu consumo religioso. 
C abefazer um parêntese para observar que esta controvérsia não concerne apenas a correntes rivais na sociologia da religião, como destacam Voas, O Ison eC rockett (2002, p. 213), mas a todos osinteressados no debateacerca da natureza da própria modernidade, tendo em vista que, para Finke e Stark, a modernização, semprequeacompanhada da desregulação estatal da religião, conduz ao pluralismo eà el evação da participação religiosa. Adversário da teoria da secularização, o novo paradigma considera o pluralismo religioso arauto de uma era de ouro sem precedentes para a religião (cf. Buyukokutan, 2006, p. 3). Em suma, estão em disputa concepções rivais sobre a modernidade (ou suas congêneres antecedidas pelos prefixos pós, hiper, tardo), uma que aposta num mundo mais secular tanto na vida privada como na pública, outra que divisa uma sociedade com alta participação religiosa, situação em queas religiões detêm maior probabilidade de exercer influência na esferajurídico-política.

$N$ este contexto de mercado, não éa liberdade somente das organizações religiosas que está em pauta e que tem efeito sobre a religião, mas também a dos consumidores. A liberdade de escolha dos consumidores religiosos, segundo I annaccone (1997, p. 27), tende a constranger mais pronunciadamente os provedores religiosos onde há menor regulação estatal e maior competição. Para granjear maior aceitação dos leigos que os concorrentes, nessa situação, os grupos religiosos são impelidos a moldar o conteúdo de seus serviços e produtos às preferências dos consumidores. Para sobreviver em ambientes competitivos, eles não têm escolha a não ser abandonar modos ineficientes de produção eprodutos religiosos impopulares em favor de outros mais atraentes (cf. Iannaccone, 1995, p. 77).

A proposição de que o pluralismo religioso (por gerar competição) aumenta o vigor dos produtores religiosos e os níveis de participação religiosa veio a público na segunda metadedosanos de 1980 (cf. Stark, 1985; Finkee Stark, 1988). N a década seguinte, proliferaram pesqui sas para testar sua validade, acirrando o debateentre seus defensores eoponentesatéao ponto de enredá-lo em intrincadas controvérsias metodológicas. Iannaccone (1997, p. 40), por exemplo, efetuou estudo sobre a participação religiosa da população de dezessete nações ocidentais, encontrando "taxas de freqüência e crença religiosas significativamentemais al tas em países com maior pluralismo religioso". Em 2001, Chaves e Gorski (2001, pp. 262-263) compulsaram 26 artigos publicados baseados em pesquisas quantitativas sobre 0 tema, nos quais encontraram 193 análises de correlações bivariadas ou parciais entre pluralismo religioso e participação religiosa. Retornando ao iní- 
cio desse debate, esses autores ressaltam que, no final dos anos de 1980, Finke e Stark (1988) cometeram erro metodológico na análise dos dados relativos ao pluralismo eà participação de religiosos nas cidades norte-americanas em 1906, ao obter correlação positiva entre ambas as variáveis somentepor meio daadoção deum controlesobrea porcentagem decatólicos, recurso que gerou um efeito matemático artificial nos resultados da pesquisa, favorável à sua tese, conforme apontara Breault já em 1989 (cf. Chavese G orski, 2001, pp. 266-269). No mesmo trabal ho, Breault encontrou ainda uma correlação negativa entre plural ismo e participação religiosa nos dados de 1980 dos condados dos Estados U nidos. N a época, Finke e Stark foram bem-sucedidos em desancar Breault, pondo em xeque a correção factual ea credibilidade de seu trabalho. Somente uma década mais tarde, relatam Chaves e Gorski (2001), foi comprovado, por D aniel O Ison (1999), o acerto inicial de Breault acerca da incorreção dos cál culos e resultados originais da pesquisa dosteóricos da escol haracional da religião. Paratestar a proposição, C haves e Gorski restringiram-se ao exame das análises (93 casos) que tinham como variável dependentea participação religiosa global da população. A pós corrigi rem o erro apontado por 0 Ison e recal cularem as 93 análises, concluíram quea associação entre pluralismo e participação religiosa revelou-se positiva somenteem onze casos, mas negativa ou nula em 82 deles, resultados que, a seu ver, refutam a perspectiva sustentada por FinkeeStark (cf. Chaves e G orski, 2001, p. 269).

Contudo, no ano seguinte à publicação do artigo de Chaves e G orski, Voas, O Ison eC rockett (2002) comprovaram a invalidadedetodosos resultados quantitativos obtidos até então, mostrando que a medida de pluralismo religioso adotada pelos pesquisadores, o $\mathrm{H}$ erfindahl index - usado por economistas para mensurar a concentração dos mercados de produtos -, distorcia-os artificialmente, ao manter uma correlação não-zero entre pluralismo e participação mesmo quando não existia relação substantiva entre as variáveis. Portanto, nem as correlações positivas encontradas entre pluralismo e participação nem as negativas eram válidas para atestar ou refutar a teoria.

Diantedesse problema, M ontgomery (2003) formulaum model o econômico formal, composto por nova medida de competição, para avaliar a teoria, usando, tal como outrospesquisadores, dados do censo dascidades do estado de N ova York, de 1865, e do censo de denominações nos condados americanos de 1990. Embora insista na necessidade da realização de outras pesquisas para determinar se a relação entrecompetição e participação écau- 
sal ou não, conclui que, no caso das cidades de N ova York, os mercados religiosos mais competitivos (com mais opções) apresentam maior participação religiosa, enquanto nos condados americanos ocorreo oposto, isto é, os condados com mais opções apresentam menor participação religiosa (cf. I dem, p. 805). M as isso não o levaa refutar a teoria deStark ecompanhia. Considera-a compatível com seus dados empíricos desde que os proponentes da versão forte da teoria da escol ha racional admitam queas denominações religiosas apresentam diversidade interna capaz de apelar a diferentes tipos de consumidores ${ }^{3}$ (o que permitiria aliar alta participação com baixo pluralismo), que eles superem a fal sa dicotomia explicativa entre oferta e demanda, reconheçam a existência de variação significativa nas demandas religiosas e considerem queas diferenças na participação também podem ser conduzidas mais pelas forças da demanda do que pelas da oferta (cf. I dem, pp. 797-806). Avesso à versão radical do novo paradigma, M ontgomery procura acentuar a relevância explicativa da análise da demanda. Ao mesmo tempo, porém, de fendeque não há como sustentar que a participação religiosa independedas ações do clero, das congregações edas denominações. 0 pta, assim, por combinar demanda e oferta para explicar os níveis de partici pação religiosa.

No plano histórico, C haves e G orski (2001, p. 270) reconhecem exemplos que reiteram a teoria de Stark, como no caso dos baixos níveis de vitalidade nas economias religiosas escandinavas confessional mente homogêneas (luteranas) e reguladas pelo Estado, comparados aos das mais pluralistas e desreguladas da G rã-B retanha, da H olanda e da Alemanha. Por outro lado, Steve Bruce $(2000$, p. 38) mostra que a diminuição da regulação estatal das economias religiosas da Finlândia, da D inamarca, da Suécia e da N oruega foi acompanhada pelo declínio de sua vitalidade. N esse mesmo sentido, Bruce (1999) e C haves e G orski (2001) apontam a concomitância da diminuição da regulação estatal, do aumento do pluralismo e do declínio da participação religiosa na Europa pós-guerra e no C anadá, tendências históricas incompatíveis com as ambiciosas proposições universalistas da teoria da escolha racional da religião. Cumpre frisar que, ao contrário de Stephen Warner (2003), que limitou o novo paradigma da sociologia da religião à economia religiosa dos Estados Unidos, onde vigora um livre mercado religioso, Stark, Finke el annaccone apostam na sua validade universal (cf. Sharot, 2002, p. 428). Q uanto ao caso americano, Chaves eG orski (2001, p. 272) questionam a suposta ampliação da proporção de religiosos na população estadunidense nos séculos XIX e XX, ponderando que os critérios de pertença religiosa nos Estados U nidos - nos quais se baseiam
3. Para Finke, Stark e Iannaccone, asorganizações religiosas que care cem deuma hierarquia central organizada, caso dos batistas com seu governo eclesiástico congregacionalista, ou que nutrem compromisso ins titucional com o pluralismointerno, caso dal gre jaCatólica, podem oferecer elevadadiversidade debenseserviçosreligiososa diferentespúblicos (cf. Sherkat e Ellison, 1999, p. 379). Tal perspectivapermiteconciliar o novo paradigma comaevidênciaempírica de que Polônia e Irlanda, países majoritariamente católicos e com pouco pluralismo, apresentam altas taxas departicipação religiosa e freqüência às missas católicas. 
Finke eStark - afrouxaram-se nesse período, tornando os níveis de pertencimento formal mais altos do que os de freqüência efetiva aos cultos. Jogando água nesse moinho, $\mathrm{H}$ adaway, $\mathrm{M}$ arler e C haves (1998) descobriram que a freqüência aos cultos de fim de semana nas igrejas norte-americanas está substantivamente abaixo do que aponta a maioria dos surveys e das pesquisas de opinião.

Por outro lado, há casos históricos de economias religiosas que se enquadram plenamente na explicação do novo paradigma. Finke argumenta:

0 Japão pós-2a - Guerra M undial serve como um dos muitos exemplos. Antes do fim da $2 \mathrm{a}$ G uerra M undial, o governo controlava estritamente a atividade religiosa no Japão. 0 Estado subsidiava os santuários xintó e a participação nas cerimônias xintoístas era uma matéria de dever cívico. As religiões alternativas requeriam reconhecimento do governo para existir legalmentee, uma vez reconhecidas, enfrentavam interferência, supressão e perseguição do Estado. [...] M as a derrota japonesa ea ocupação aliada em 1945 levaram a uma imediata abolição de todas as leis que controlavam a religião, separando a religião xintó do Estado e concedendo liberdade religiosa sem precedentes. [...] N ovas religiões brotaram como cogumelos de pois da chuva. [...] Alguns têm argumentado que foi a demanda por religião, não a oferta, que mudou mais dramaticamente na esteira da 2a Guerra M undial. Essa explicação [...] sugere que, quando as pessoas estão diante de expectativas frustradas, instabilidade social e uma perda de fé nas instituições tradicionais, elas procurarão novas religiões que ofereçam novas respostas. [...] Rejeito este argumento por várias razões. Primeiro, a derrota japonesa não deu início a um processo de expansão do escapismo espiritual: as religiões tradicionais não experimentaram aumento no número de membros ou na devoção. Segundo, o crescimento de novas religiões continuou muito depois que a economia japonesa se recuperou e continua ainda hoje. Terceiro, a Alemanha compartilhou a derrota japonesa, mas sua economia religiosa permaneceu altamente regulada e não experimentou um boom de novas religiões no pós-guerra (1997, pp. 47-48).

Apesar de inconclusas - uma vez que existem evidências históricas tanto contrárias como favoráveis à relação entre pluralismo e participação religiosa - , as disputas teóricas e metodológicas supracitadas permitem ao menos concluir queregulação estatal, pluralismo e competição, independentemente de seu menor ou maior impacto sobre a oferta e o ativismo dos produtores religiosos, são insuficientes para explicar os níveis de participação em uma dada economia religiosa. As variáveis independentes pluralismo e competi- 
ção não dão conta dessa questão. H á outros fatores importantes em jogo, incluindo os relativos à demanda. Para explicar, por exemplo, por que a Finlândia apresenta nível de participação religiosa mais elevado do que seus vizinhos nórdicos, apesar de ter religião hegemônica e histórico de regulação estatal semelhantes, Steve Bruce (2000, p. 40) observa que esse país é menos urbano, possui menor renda média e tem sua integridade nacional associada ao luteranismo, que desempenhou importante papel na luta contra o domínio russo, que perdurou até 1917. Ao associar modernização econômica e social e declínio do compromisso religioso (argumento clássico da teoria da secularização), e identificar luteranismo e nacionalidade finlandesa, Bruce argumenta que esses fatores atuam sobre a demanda religiosa - isto é, sobre gostos, preferências e escolhas individuais e coletivos para explicar a diferença entre os níveis de participação religiosa na Finlândia e nos seus vizinhos. N essa explicação, o luteranismo finlandês não é encarado necessariamente como produtor religioso mais eficiente do que seus co-irmãos nórdicos; sua eficiência na elevação do nível de participação religiosa resulta de seu vínculo com a luta pela libertação nacional e da baixa modernização econômica relativa da Finlândia. Em sua argumentação, Bruce examina processos históricos distintos e compara relações entre I greja, Estado, identidade eindependência nacionais, dimensões, em geral, marginalizadas pelo novo paradigma, excetuando a relação I greja-Estado e a regulação estatal das economias religiosas4.

São freqüentes as críticas ao novo paradigma para que incorpore efetivamente a análise da demanda e pondere as razões históricas e macrossociais de sua variação ao longo do tempo e do espaço, em vez de considerálla relativamente estável. A esse respeito, contudo, cabe notar queas noções de regulação estatal, mercado livre, monopólio, pluralismo, firmas religiosas, mercado e competição constituem fatores contextuais atuantes sobre os produtores e consumidores religiosos. O u seja, embora restrita, a contextualização tanto da oferta como da demanda não está ausente do novo paradigma. No entanto, são evidentes suas limitações na pesquisa da demanda, ou dos constrangimentos culturais, sociais e políticos sobre as escolhas religiosas individuais. Finke (1997, p. 48) reconhece que "os mercados religiosos devem seus resultados a ambas as forças da oferta e da demanda", mas restringe sua análise à oferta. Problema de peso. Pois, considerando que "as identidades das pessoas, as escolhas e mesmo seu senso de autointeresse parecem ser formados por seu contexto social", pontifica M ellor (2000, p. 283), o novo paradigma torna-se muito limitado, a menos que
4. Stark e Iannaccone (1994), curiosamente, ao analisarem o caso da Irlanda, introduzem uma explicação exterior aos axiomas da teoria da escolha racional da religião, argumentando que, numa situação de conflito, quando uma religião se torna veículo primário de nacionalismo ou etnicidade, ela pode substituir a competição religiosa, elucidando, assim, 0 alto nível de participação religiosa (cf. Sharot, 2002, p. 442). 
leve a sério as questões contextuais. Torna-se incontornável, portanto, a pesquisa do contexto de tomada de decisão para além dos fatores estritamente internos às economias e firmas religiosas, uma vez que a escol ha não se processa num vácuo social, nem é limitada tão-somente pelas opções e ofertas de mercado, nem pela regulação estatal. São várias as mediações sociais que influenciam, moldam e limitam as preferências e as escolhas religiosas individuais e coletivas (cf. Sherkat, 1997). Finke (1997, p. 57) reconhece uma delas, afirmando que as subculturas locais podem restringir as escolhas e alterar as preferências religiosas de seus consumidores religiosos. M as é pouco. "A adesão à fé", afirma M aria Lucia M ontes (1998, p. 141), "pressupõe um trabalho mais amplo do social, que, anterior aos indivíduos, molda para ele suas 'opções' no campo religioso". D aí sua crítica à teoria do mercado de bens de sal vação, dominada pela lógica do interesse, por encarar a escolha religiosa, fundamentalmente, como uma questão de ordem individual. Para M ontes,

[...] na delicada trama social que sustenta, para os homens, a credibilidade de um sistema de interpretação de sua experiência do mundo, entre o indivíduo e a sociedade interpõe-se uma infinidade de mediações. No caso da religião, como se sabe, as instituições - igrejas, templos, sinagogas, terreiros, centros, e as organizações mais abrangentes de que são parte - responsáveis pela sistematização e tran smissão das crenças, assim como das práticas litúrgicas, nos rituais e nos cultos, constituem mediações essenciais. C ontudo, elas não são as únicas, já que, para além da organização interna do sagrado, na crença e na prática ritual e devocional, outros sistemas de valores e práticas ritualizadas, ligados a outras dimensões profanas da vida social, com suas miríades de símbolos e signos, dialogam com esse sistema interpretativo, passíveis ou não de ratificá-los ou se mostrar com eles compatíveis. É assim que, nas sociedades, se constituem comunidades de sentido mais ou menos abrangentes: é em função delas que a experiência do mundo se torna interpretável eé no seu interior que também se define o lugar da religião (I dem, p. 139).

Reconhecer tais limitações do novo paradigma, porém, não implica descartá-lo. Até porque dificilmente se podenegar sua relevância heurística na renovação teórica e empírica da sociologia da religião contemporânea. $M$ ais que isso: dado que por muito tempo a ênfase teórica incidiu justamente sobre a demanda, verifica-se que ele teve o mérito de revelar a elevada potencialidade analítica da oferta, que estava relegada a segundo plano, e interpretá-la com base num enfoque inovador. 
Contudo, a analogia com o mercado econômico, ao mesmo tempo em que inova, limita este enfoque, já que muito do funcionamento, da organização e do comportamento de agentes e produtores religiosos escapa à embocadura dos insights derivados da microeconomia. 0 novo paradigma ignora, por exemplo, as "organizações religiosas que não demandam compromisso exclusivo deseus seguidores", restringindo-se, em grande parte, às economias religiosas ocidentais e, em especial, aos grupos religiosos compostos por congregações, que em geral procuram fidelizar seus membros (cf. Sharot, 2002, pp. 443-444). N ão édifícil perceber as razões disso. Weber (1991, p. 313) advertiu que "quanto mais especificamente congregacional o caráter da organização, tanto mais a posição poderosa dos sacerdotes enfrenta a necessidade deter em conta, no interesse da conservação e propagação do grupo de adeptos, as necessidades dos leigos". A ênfase de Weber sobre a imperiosa necessidade de os dirigentes congregacionais, na defesa de seus poderes sacerdotais e interesses institucionais, fazerem concessões às demandas proféticas, tradicional istas e intelectualistas dos leigos decorre, em grande parte, do caráter exclusivista do compromisso religioso exigido dos fiéis, especialmente nas religiões monoteístas. A análise weberiana está em consonância com o raciocínio - focado na oferta - de que, para compreender o sucesso (manutenção e expansão da base de adeptos) ou fracasso institucional dos grupos religiosos, é preciso atentar para as pressões sobre seus dirigentes e analisar suas ações e estratégias visando a atender às demandas dos consumidores e fidelizá-los. Por demandarem freqüentemente compromissos exclusivos, as religiões congregacionais constituem excelente objeto de estudo para o novo paradigma, focado na ação e nas estratégias institucionais dos produtores religiosos, na racionalidade instrumental dos consumidores ena lógica de mercado. Por outro lado, entretanto, tal enfoquetendea revelar-se pouco apropriado eaté "irrelevante", na opinião de Sharot (2002, pp. 443-445), para analisar economias formadaspor religiões não-monoteístas, majoritariamentenão-exclusivistas, epelas orientais, nas quais a mai oria dos leigos "carece de quaisquer laços organizacionais formais com templos e sacerdotes".

A teoria da escolha racional da religião reúne, portanto, maior aptidão para analisar economias religiosas desreguladas, pluralistas, competitivas, dotadas de mercados livres e de grupos religiosos que demandam compromissos exclusivos de seus adeptos. $\mathrm{N}$ a real ização dessa tarefa, prioriza a investi gação dos fatores internos das economias religiosas, limitando sua análise contextual aos fatores externos que considera atuantes diretamente sobre 
5. Sobre a abordagem sociológica clássica do pentecostalismo no Brasil, ver M ariano (2001).

6. $\mathrm{N}$ a exposição da importância da stricteness para o vigor dos grupos religiosos, os autores do novo paradigma têm como fonte básica, além da teoria da escoIha racional, o trabalho deD ean Kelley (1986), publicado originalmente em 1972, que associou o declínio dasigrejas protestantes liberais norte-americanas a traços deleniência esecularização interna, e, em contraste, o sucesso dos mórmons, testemunhas-de-jeová, pentecostais e outras seitas a seu sectarismo e rigorismo comportamental. o mercado e os produtores religiosos, dentre os quais sobressai a regulação estatal.

Para exemplificar como esta abordagem difere da anterior, focada na de manda, discorro, sucintamente, sobre a teoria sociológica clássica sobre a expansão pentecostal no Brasil ${ }^{5}$. D ecunho funcionalista, ela confere primazia às transformações macroestruturais da sociedade pela geração de certas demandas sociais e pela mudança nas escol has religiosas de parte da população brasileira, em especial dos estratosmais pobres edosmigrantes rurais. A transição da soci edade tradicional para o capitalismo moderno, por meio da industrialização, do desenraizamento social, da migração, da urbanização e da proletarização, provoca anomia nos migrantes rurais e exclusão social das massas pobres, que encontram nas igrejas pentecostais respostas a tais problemas. Assim, as igrejas funcionam como mecanismos de integração, solidariedade, restitui ção da ordem psíquica e segurança identitária. Enquanto o processo de modernização não findar, prosseguirá a formação de tais de mandas sociais que impulsionam a expansão pentecostal. Pondo de lado os problemas da corrente funcionalista, já há muito debatidos, observa-se que a análise focada na demanda centra-se em fatores extra-religiosos genéricos supostamente responsáveis pela mudança nas escolhas religiosas dos que aderiram às igrejas pentecostais, vistas, em certa medida, como respostas mecânicas a estímulos exteriores. Sua principal limitação é a incapacidade de explicar a enorme desigualdade na performance numérica e na organização institucional das igrejas pentecostais presentes nos grandes centros urbanos, cujos portes variam de grupos de fundo de garagem a verdadeiras multinacionais da fé. Para compreender esse fenômeno, o foco na oferta constitui, disparado, a melhor opção analítica, o que não implica desconsiderar os fatores contextuais atuantes sobre a demanda.

Stricteness e vigor dos grupos religiosos

Stark (1996) apresenta proposições sobre as condições para o sucesso ou fracasso dos grupos religiosos em economias desreguladas, conferindo destaque ao papel do rigor sectário para a vitalidade institucional. Para crescer, um grupo religioso deve manter alta tensão com a cultura ambiente, ser distintivo e impor padrões morais relativamente rigorosos (cf. I dem, p. 137). Isto é, deve ser sectário e ter stricteness (cf. Stark, 1996; Iannaccone, 1994, Finke, 1997) ${ }^{6}$. Stricteness refere-se ao grupo religioso que mantém "um estilo de vida distintivo e separado na moralidade pessoal e na vida 
familiar, em áreas como vestimenta, alimentação, bebida, entretenimento, uso do tempo, sexo, criação dos filhos" (Stark, 1999a, p. 137). A stricteness, além de demarcar traços distintivos e sectários, torna os grupos religiosos fortes ao barrar os freeriders, que prejudicam a ação coletiva por compartiIhar dos benefícios sem contribuir, desestimulando, assim, o efforço ea virtude dos demais. A criação de barreiras para entrar no grupo, por meio de exigências custosas, obriga seus membros a se qualificarem para acatar os sacrifícios demandados de todos, ampliando, em conseqüência, seu nível médio de compromisso7. Altos níveis de compromisso, por sua vez, resultam em maiores produção e consumo coletivos de bens religiosos, como cultos, sermões, liturgia e louvor participativos e entusiásticos (cf. Finke, 1997, pp. 52-54; Iannaccone, 1994, p. 1184). Contudo, strictness em de masia prejudica. Por isso, deve ser al ta o bastante para afastar os caronistase arredios, mas "suficientemente bai xa para não afastar todos exceto uns poucos desajustados e fanáticos" (Stark, 1996, p. 138).

Para ser bem-sucedido, um grupo religioso precisa oferecer mais recompensas do que exigir sacrifícios. Para tanto, tem duas opções: aumentar os bens e serviços ofertados ou diminuir os custos para os membros. M aisfácil e tentadora, esta opção tende a precipitar o processo de transformação de seitas em igrejas, definidas (em oposição às primeiras) pelo baixo grau de tensão com a cultura ambiente. A redução dos custos e da tensão, contudo, resulta no relaxamento do comportamento e do compromisso dos adeptos e, com isso, na queda da produção edo consumo coletivos debens religiosos (cf. Finke, 1997). D aí o declínio dos grupos que reduzem suas exigências, medida geral menteacompanhada pela irrupção de dissidências para formar novas seitas. U ma das principais pressões para reduzir o rigor sectário costuma partir das novas gerações de membros, que, por terem nascido na religião e não terem efetuado uma adesão voluntária ao grupo religioso rigoroso, tendem a demandar a diminuição dos sacrifícios comportamentais. Se ceder a tal pressão resulta na perda de vigor coletivo, a opção por manter elevados custos de pertença e participação também enfrenta dificuldades, pois depende da eficácia da socialização religiosa para gerar obediência à stricteness e evitar elevado número de defecções (cf. Stark, 1996, pp. 143144). M as compensa. Pesquisas realizadas nos Estados U nidos confirmam que, comparados aos adeptos de denominações protestantes liberais e moderadas, os membros das seitas contribuem mais financei ramente, freqüentam mais os cultos, mantêm crenças mais fortes, pertencem a mais grupos religiosos internos e são menos envolvidos em organizações seculares (cf.
7. 0 queestáimplicado na explicação do "poder coercitivo das igre jas estritaséa possibilidadedequeasescolhas racionais dos indivíduos, e de suas ações, sejam formadasnormativamentepelacomunidade" (M ellor, 2000, p. 282). Na medida em que normas e valores contribuem para a formação dastricteness, não podem ser descartados da análise. 
Iannaccone, 1994, p. 1994). Submetidosa maiores exigências, os membros das seitas são, em geral, mais ativos e comprometidos.

U ma objeção a essa perspectiva éa subjetividade envolvida na mensuração de recompensas e exigências. 0 s leigos, por exemplo, podem encará-las de modos muito distintos quanto a seu valor eao sacrifício, respectivamente (cf. Bruce, 1999). I annaccone reconhece que "medidas objetivas" sobrea stricteness "são difíceis de obter" (1994, pp. 1188-1192), mas insiste que é possível verificar e comparar sua maior ou menor intensidade nos diferentes grupos religiosos. Em relação ao comportamento maximizador e às recompensas, resta "especificar mais precisamente o que está sendo maximizado" (M ontgomery, 2003, p. 805). N esse ponto, Stark destaca a importância das trocas sociais nos grupos religiosos sectários.

O compromisso religioso é sustentado por "vínculos interpessoais", por meio dos quais os indivíduos vivenciam e avaliam sua religião (cf. Stark, 1996). As "relações pessoais são parte das recompensas tangíveis da participação em um movimento religioso", sendo afeição, respeito, sociabilidadee companheirismo bens detroca vitais (cf. Idem, p. 142). Compromissos religiosos sólidos e redes de sociabilidade fortes parecem nutrir-se mutuamente. Basta ver que, enquanto pequena minoria dos protestantes liberais relata ter amigos pessoais próximos entre os fiéis de sua congregação local, a maioria dos membros das seitas protestantes afirma quea maior parte ou todos os seus mel hores amigos são de sua congregação (cf. I dem, p. 142). 0 s grupos religiosos só serão bem-sucedidos, porém, se sustentarem fortes relações internas e, simultaneamente, "permanecerem como uma rede social aberta, capaz de manter eformar laços com os de fora" (I dem, pp.142-143).

0 núcleo dessa argumentação atribui enorme peso explicativo à stricte ness. Ao considerá-la a chave do "moral elevado" e do "rápido crescimento" religioso, Stark (1996, p. 143) marginaliza fatores relevantes para a compreensão desse fenômeno. Veja-se o caso, por exemplo, da I greja U niversal, quepodeser definida como seita por sua elevadatensão com a cultura nacional. Por conta do evangelismo eletrônico, dos megatemplos, das fartas promessas debênçãos de prosperidadematerial edecultos demassa, a U niversal apresenta elevado contingente de clientes - free riders- à procura de graças pontuais, o que deveria resultar em baixo compromisso e declínio numérico, ainda mais por cobrar, com a importante exceção do sacrifício financeiro, custos comportamentais relativamente baixos. No entanto, dados da pesquisa N ovo N ascimento, realizada em meados dos anos de 1990 no Rio deJaneiro, reiteram a teoria da stricteness, ao revelar que os fiéis da U niversal 
participaram menos do evangelismo no mêsanterior à pesquisa queseuspares de outras igrejas, mas, por outro lado, colocam essa teoria em xeque, ao mostrar que eles pagaram proporcionalmente mais dízimos e ofertas, efreqüentaram mais os cultos, o que evidencia custos e compromissos el evados (cf. Fernandes, 1998).

Pode-se anal isar a expansão dessa denominação considerando-se outros fatores, focados na oferta, além da stricteness. Em relação aos dados citados, por exemplo, observa-se que a U niversal compensa a baixa militância dos fiéis com a estratégia de conferir às lideranças eclesiásticas, escudadas por dezenas de milhares de obreiros, a tarefa de concentrar os esforços proselitistas, comandando o evangelismo eletrônico ea oferta sistemática de serviços mágico-religiosos adaptados a demandas materiais e espirituais dos estratos pobres da população ${ }^{8}$. A elevada freqüência a seus cultos decorre, em parte, da realização de correntes nas quais os adeptos precisam comparecer, impreterivelmente, por semanas a fio, para não quebrá-las eangariar os efeitos mágicos propostos e desejados. Já sua reconhecida eficiência em obter el evado sacrifício financeiro dos fiéis se deveà implacável cobrança do pagamento de dízimos e ofertas e ao êxito persuasivo - apoiado na teologia da prosperidade e em infindáveis testemunhos de sucesso material - em convencêlos de que somente assim expressam sua fé, tornam-se "sócios de D eus" e aptos a receber bênçãos em "abundância".

A economia religiosa brasileira contemporânea é pluralista, competitiva e funciona como um mercado livre, apesar da hegemonia e da maior legitimidade social da I greja $C$ atólica, e dos privilégios estatais de que usufrui. Por isso, o contexto brasileiro constitui excelente campo de aplicação eteste da teoria da escolha racional da religião. Tanto por se destacar nesse mercado como por seu denodo proselitista, a vertente pentecostal compõe objeto depesquisa quese encai xa como uma luva nessa perspectiva teórica. Pois, do lado da oferta, diversas igrejas pentecostais apresentam ampla disposição para enfrentar a concorrência, competir por mercado, fazer proselitismo, criar novas demandas, exigir compromisso exclusivo dos adeptos, adotar técnicas publicitárias, estratégias demarketing emétodos de gestão eorganização típicos da racionalidade econômica. D o lado da demanda, por sua vez, verifica-se a presença, em larga escala, de uma racionalidadeinstrumental fomentada pela oferta de serviços mágicos e por promessas de benefícios materiais e espirituais baseadas em relações de reciprocidade e de troca.

Por fim, cabe observar que esse enfoque tende a hipertrofiar o papel das lideranças religiosas, a reduzir a agência dos leigos e a relegar a segundo
8. Por meio da aplicação de um survey, Alexandre Fonseca (1997, p. 190) constatou que para $50,3 \%$ dos adeptosda Universal no Rio de Janeiro sua conversão foi influenciada por rádio (32\%) etel evisão $(18,3 \%)$. 
plano os grupos bem-sucedidos desprovidos de estruturas organizacionaise finanças centralizadas (cf. Buyukokutan, 2006, p. 8). Apresenta ainda 0 risco de incorrer em perspectivas mecanicistas e deterministas, se conduzir ao pressuposto de que os imperativos do mercado se impõem automaticamente sobre os grupos religiosos atuantes num contexto competitivo ou de mercado. Para evitá-las, cumpre verificar como as lideranças religiosas integram os constrangimentos internos e externos em seus cálculos e, se o fazem, como agem estrategicamente a partir disso (cf. Friedberg, 1993). No caso do pentecostalismo brasileiro, por exemplo, observa-se tanto a emulação de práticas e estratégias expansionistas bem-sucedidas da U niversal por parte de líderes de outras agremiações pentecostais, como acentuada resistência e rejeição a elas, motivadas, neste caso, por princípios éticos, razões doutrinárias, sectarismo e tradicionalismo. Esses comportamentos díspares indicam a existência de vários e divergentes imperativos (além dos mercadológicos), racionalidades, motivações e interesses em jogo nesses grupos religiosos, dependentes de diferentes trajetórias históricas, tradições denominacionais, contextos de ação religiosa e mediações socioculturais.

\section{Referências Bibliográficas}

Abram ovay, Ricardo. (2004), “Entre D eus e o D iabo: mercados e interação humana nas Ciências Sociais". Tempo Social - Revista de Sociologia da U SP, 16 (2): 35-64. BAERT, Patrick. (1997), "Algumas limitações das explicações da escolha racional na Ciência Política ena Sociologia". Revista Brasile ra deCiênciasSociais, 12 (35): 63-74.

Berger, Peter L. (1985), 0 dossel sagrado: elementos para uma sociologia da religião. São Paulo, Paulinas.

BRUCE, Steve. (1999), Choice and religion: a critique of rational choice theory. O xford, Oxford University Press.

. (2000), "The supply-side model of religion: the Nordic and Baltic States". Journal for the Scientific Study of Religion, 13 (1): 32-46.

BuYukO KutAn, Baris. (2006), "Evaluating rational choice theories of religion". Paper presented at the annual meeting of the American Sociological Association, M ontreal, Quebec, Canada, disponível em http://www.allacademic.com/meta/ p103187_index.html, consultado em 01/7/2008.

Chaves, Mark \& Gorskı, Philip S. (1995), “On the rational choice approach to religion". Journal for the Scientific Study of Religion, 34 (1): 98-104.

. (2001), "Religious pluralism and religious participation". Annual Review of Sociology, 27: 261-281. 
Coluins, Randall. (1993), "Book review of A T heory of religion, by Rodney Stark and W illiams Sims Bainbridge". Journal for the Scientific Study or Religion, 32 (4): 402-406.

. (1997), "Stark and Bainbridge, D urkheim and Weber: theoretical comparisons". In: Young, Lawrence A. (org.), Rational choice theory and religion: summary and assessment. N ova York, Routledge, pp. 161-180.

Fern An D ES, Rubem César. (1998), N ovo nascimento: os evangéli cos em casa, na igreja e na política. Rio de Janeiro, M aud.

FIN KE, Roger. (1997), "T he consequences of religious competition: supply-side explanations for religious change". In: Young, Lawrence A. (org.), Rational choice theory and religion: summary and assessment. N ova York, Routledge, pp. 45-64.

Fin Ke, Roger \& Stark, Rodney. (1988), "Religious economies and sacred canopies: religious mobilization in American cities, 1906". American Sociological Review, 53: 41-49.

Fon SECA, Alexandre Brasil. (1997), Evangélicos e mídia no Brasil. Rio de Janeiro. D issertação de mestrado em Sociologia. Instituto de Filosofia e Ciências Sociais, da U niversidade Federal do Rio de Janeiro.

Fried beRG, Erhard. (1993), 0 poder e a regra: dinâmicas da ação organizada. Lisboa, Instituto Piaget.

Frigerio, Alejandro. (2000), "Teorias econômicas aplicadas ao estudo da religião: em direção a um novo paradigma?". BIB - Revista Brasileira de Informação Bibliográfica em Ciências Sociais, 50: 125-143, Rio de Janeiro.

H adaway, C. K, M arler, P. L. \& Chaves, M . (1998), "O verreporting church attendance in America: evidencethat demands the sameverdict". American Sociological Review, 63 (1): 122-130.

I AN N ACCONE, Laurence R. (1994), "W hy strict churches arestrong”. American Journal of Sociology, 99: 1180-1211.

. (1995), "Voodoo economics? Reviewing the rational choice approach to religion". Journal for the Scientific Study of Religion, 34 (1): 76-89.

. (1997), "Rational choice: framework for the scientific study of religion". In:

Young, Lawrence A. (org.), Rational choice theory and religion: summary and assessment. N ova York, Routledge, pp. 25-44.

I An naccone, Laurence, Fin Ke, Roger \& Stark, Rodney. (1997), “D eregulating religion: the economics of church and state". Economic Inquiry, 35: 350-364.

Jerolmack, Colin. (2004), "Religion, rationality, and experience: a response to the new rational choice theory of religion". Sociological Theory, 22 (1): 140-160.

KelLey, D ean M . (1986), Why conservative churches are growing. Georgia, M ercer U niversity Press. 
M ARIAn O, Ricardo. (2001), Análise sociológica do crescimento pentecostal no Brasil. Tese de doutorado. Faculdade de Filosofia, Letras e C iências H umanas da Universidade de São Paulo.

M ellor, Philip A. (2000), "Rational choice or sacred contagion? 'Rationality', 'nonrationality' and religion". Social Compass, 47 (2): 273-292.

M ontes, M aria Lucia. (1998), "As figuras do sagrado: entre o público e o privado". In: Novals, Fernando (coord.) \& Schwarcz, Lilia M. (org.), História da vida privada no Brasil: contrastes da intimidade contemporânea. São Paulo, Companhia das Letras, vol. 4, pp. 63-171.

M ONTGOM ERY, James D. (2003), "A formalization and test of the religious economies model". American Sociological Review, 68: 782-809, 0 ctober.

O Lson, Daniel V. A. (1999), "Religious pluralism and U.S. church membership: a reassessment". Sociology of Religion, 60: 149-173.

SHAROT, Stephen. (2002), "Beyond christianity: a critique of the rational choice theory of religion from a weberian and comparative religions perspective". Sociology of Religion, 63 (4): 427-454.

Shea, Chris. (2001), "Supply and demand among the faithful". N ew York T imes, 24/ 3. Sherkat, D arren E. (1997), "Embedding religious choices: preferences and social constraintsinto rational choicetheories of religious behavior". In: Young, Lawrence A. (org.), Rational choice theory and religion: summary and assessment. N ova York, Routledge, pp. 65-85.

Sherkat, D arren E. \& Ellison, Christopher G. (1999), "Recent developments and current controversies in the sociology of religion". Annual Review of Sociology, 25: 363-394.

Stark, Rodney. (1985), "From church-sect to religious economies". In: H am m Ond, Phillip E. (ed.), Thesacred in a post-secular age. Berkeley, University of C alifornia Press. . (1996), "W hy religious movements succeed or fail: a revised general model". Journal of Contemporary Religion, 11 (2): 133-146.

. (1997), "Bringing theory back in". In: Youn G, Lawrence A. (org.), Rational choicetheory and religion: summary and assessment. N ova York, R outledge, pp. 3-23. . (1999a), "M icro foundations of religion: a revised theory". Sociological Theory, 17 (3): 264-289. . (1999b), "Secularization, R.I.P". Sociology of Religion, 60 (3): 249-273.

Stark, Rodney \& Bainbridge, W illiam Sims. (1985), The future of religion: secularization, revival, and cult formation. Berkeley, U niversity of California Press. . (1996), A theory of religion. N ew Brunswick, Rutgers U niversity Press.

Stark, Rodney \& FIn KE, R oger. (2000), Acts of Faith. Berkeley, U niversity of C alifornia Press. 
Stark, Rodney \& Iannaccone, Laurence. (1992), "Sociology of religion”. In: BorgatTA, Edgar F. \& BorgatTA, M arie L. (org.), Encyclopedia of Sociology. N ova York, M acM illan Publishing Company, 4:2029-2037.

. (1993), "Rational choice propositions about religious movements". Religion and Social O rder, 3a: 241-261.

. (1994), "A supply-side reinterpretation of the 'secularization' of Europe". Journal for the Scientific Study of Religion, 33: 230-252.

Swed beRG, Richard. (2005), M ax Weber ea idéia de sociologia econômica. Rio deJ aneiro, Editora da UFRJ.

VoAs, David, O Lson, D aniel \& CRocketT, Alasdair. (2002), "Religious pluralism and participation: why previous research is wrong". American Sociological Review, 67: 212-230.

W ARn ER, Stephen. (1993), "Work in progress toward a new paradigm for the sociological study of religion in the United States". American Journal of Sociology, 98: 1044-1093.

W eber, M ax. (1991), Economia e sociedade: fundamentos da sociologia compreensiva. Brasília, Editora da UnB, vol. 1.

Williams, Rhys H. (2000), "Rational choice theory and religion: summary and assessment" (Book Review). Sociology of Religion, 61 (1).

W UthN OW, Robert. (2005), "N ew directions in the study of religion and economic life". In: Smelser, N eil J. \& Swedberg, Richard (ed.), The handbook of economic sociology. 2 ed. Princeton/O xford/N ova York, Princeton University Press/Russell Sage Foundation.

\section{Resumo}

Usos e limites da teoria da escolha racional da religião

Este artigo tem por objetivo apresentar e analisar as principais concepções teóricas propostas por Rodney Stark, Roger Finke e Laurence I annaccone, formuladores da teoria da escolha racional da religião. Sem pretender ser exaustivo, enfoca suas inovações e limitações, eo debate teórico que suscitaram, examinando as noções de racionalidade, desregulação estatal da religião, monopólio, pluralismo, competição, mercado, oferta, demanda e stricteness.

Palavras-chave: Racionalidade; Economia religiosa; M ercado; Pluralismo; Stricteness.

\section{Abstract}

Uses and limits of the rational choice theory of religion

This aim of this article is to present and analyze the main theoretical conceptions proposed by Rodney Stark, Roger Finke and Laurence lannaccone, formulators of the 
rational choice theory of religion. Without aiming to be exhaustive, it focuses on their theory's innovations and limitations and the theoretical debate provoked in its wake, examining the notions of rationality, state deregulation of religion, monopoly, pluralism, competition, market, supply, demand and 'strictness.'

Keywords: Rationality; Religious Economies; M arket; Pluralism; Strictness.

Texto recebido eaprovado em 2/9/2008.

Ricardo M ariano é doutor em sociologia pela USP, docente do Programa de Pós-Graduação em Ciências Sociais da PUCRS e pesquisador do CN Pq. E-mail: rmariano1@uo I.com.br. 